\title{
Experimental and simulation flow rate analysis of the $3 / 2$ directional pneumatic valve
}

\author{
Slawomir Blasiak ${ }^{1, *}$ Jakub E. Takosoglu ${ }^{1}$, Pawel A. Laski ${ }^{1}$, Dawid S. Pietrala ${ }^{1}$, Jaroslaw Zwierzchowski ${ }^{1}$, \\ Gabriel Bracha ${ }^{1}$, Lukasz Nowakowski ${ }^{1}$, Malgorzata Blasiak ${ }^{1}$ \\ ${ }^{1}$ Kielce University of Technology, Faculty of Mechatronics and Mechanical Engineering, \\ Aleja Tysiaclecia Panstwa Polskiego 7, 25-314 Kielce, Poland
}

\begin{abstract}
The work includes a study on the comparative analysis of two test methods. The first method numerical method, consists in determining the flow characteristics with the use of ANSYS CFX. A modeled poppet directional valve 3/2 3D CAD software - SolidWorks was used for this purpose. Based on the solid model that was developed, simulation studies of the air flow through the way valve in the software for computational fluid dynamics Ansys CFX were conducted. The second method - experimental, entailed conducting tests on a specially constructed test stand. The comparison of the test results obtained on the basis of both methods made it possible to determine the cross-correlation. High compatibility of the results confirms the usefulness of the numerical procedures. Thus, they might serve to determine the flow characteristics of directional valves as an alternative to a costly and time-consuming test stand.
\end{abstract}

\section{Introduction}

Pneumatics along with hydraulics and electrics is the most commonly used technique for automation of industrial processes. Practically, each production machine or production line consists of drive and pneumatic control elements. The popularity of pneumatic drives results from many advantages which include i.a. availability of pressurized air almost in every industrial facility. Pneumatic drives are characterized by high dynamics, reliability and long life, ease of use, noncomplicated control systems, simple automation of processes and the fact that they can withstand strong forces. There is no need to use drive overload safety systems as in the case of the electric drives.

Pneumatic drives are controlled with the use of pneumatic divide valves. The main parameters of the divide valves include: the number of channels, number of positions, maximum pressure of working medium, nominal flow rate, switching time and idle time, as well as the size of their channel openings. With respect to the technical solutions applied therein, valves are classified into: spool, poppet and ball valves. In terms of their manner of operation, they are divided into: electrically and mechanically operated, hand- or foot-operated, pneumatically operated via pressure increase/decrease, and spring operated valves. Taking the applied materials into consideration [1,2], valves are the most commonly classified as well into: aluminum valves, plastic valves, valves made of brass or other similar materials allowed in hazardous areas with risk of explosion, e.g. mines. Valves are manufactured using various technologies. The oldest technologies include casting and machining, whereas the most modern ones include production with the use of injection plastics-moulding. The variety of the divide valve parameters, environments they can operate in, production processes or manufacturing techniques and technologies poses many problems [3-20]. Classic approach of designing divide valves used currently is time consuming and expensive. It requires developers to make projects, technical drawings, technical documentation, develop technologies, create valve prototypes, test them under laboratory conditions in order to determine the technical and operational parameters, and conduct durability tests. If the valve meets the assumed requirements, the process is completed and the prototype can be implemented into the manufacturing process, and if not - the whole process starts over again.

Recently there has been many research works concerning the flow analysis [8,16,18,19,21-33], optimization of working medium flow and different types of valves. Programs based on Computational Fluid Dynamics allowing to conduct computer simulations, which reflect the nature of the physical phenomena quite well, are becoming increasingly important. The authors used that type of calculation tools in order to determine the local changes of flow, pressure etc. Studies which intended to compare the results obtained on the basis of numerical tests with the results achieved on a test stand were also conducted [34].

\section{Valve solid model}

The assembly drawing and the solid model of the $3 / 2$ valve is presented in Fig. 1. In the initial position, the

*Corresponding author: sblasiak@tu.kielce.pl 
medium flows between channels 1-2, whereas channel 3 is cut-off, and after setting the piston in the opposite extreme position - the medium flows through channels 23 , while channel 1 is cut-off.

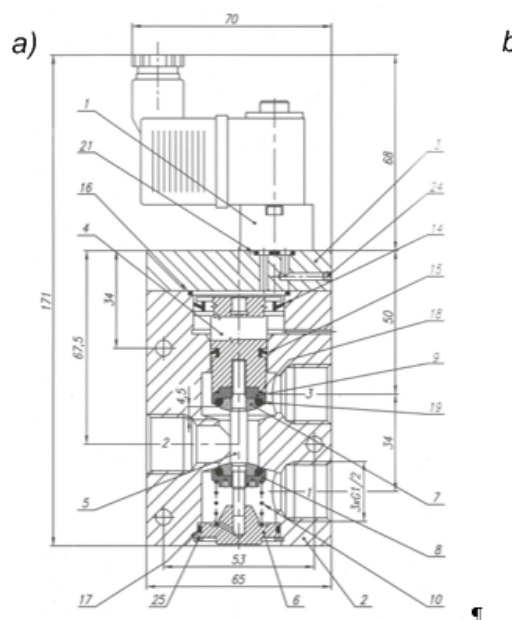

b)

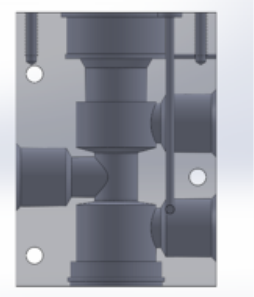

Fig. 1. 3/2 Poppet valve, a) Assembly drawing, b) Solid model.

$3 / 2$ divide valves currently belong to the group of the most frequently used valves in pneumatic drive and control systems.

Table 1. Poppet valve operating parameters.

\begin{tabular}{|c|c|}
\hline Working medium & $\begin{array}{c}\text { Pressurized air or gas with } \\
\text { similar properties, } \\
\text { filtered with max. size of } \\
\text { solids of } \mathbf{4 0} \boldsymbol{\mu m}, \\
\text { lubricated or not lubricated } \\
\text { with oil mist }\end{array}$ \\
\hline $\begin{array}{c}\text { Operating pressure } \\
\text { range }\end{array}$ & $0.25 \div 1.0 \mathrm{MPa}$ \\
\hline $\begin{array}{c}\text { Operating temperature } \\
\text { range }\end{array}$ & $-10 \div+60{ }^{\circ} \mathrm{C}$ \\
\hline Type of design & Mushroom \\
\hline Position of operation & Any \\
\hline
\end{tabular}

\section{Mathematical model of fluid flow}

In the calculation process, two principles of fluid movement were used, building a mathematical model of the divide valve in the form of equations describing the physics of the flow. Turbulent movement of viscous fluid is described with the use of Reynolds average Navier-Stokes equations (2)-(4), which together with continuity equation (1) constitute a complete system of relations which allows to determine pressure as well as velocity field of the fluid flow.

$$
\frac{\partial \rho}{\partial t}+\operatorname{div}(\rho \mathbf{U})=0
$$

$$
\begin{aligned}
& \quad \frac{\partial(\rho U)}{\partial t}+\operatorname{div}(\rho U \mathbf{U})=-\frac{\partial P}{\partial x}+\operatorname{div}(\mu \operatorname{grad} U)+ \\
& +\left[-\frac{\partial\left(\rho \overline{u^{\prime 2}}\right)}{\partial x}-\frac{\partial\left(\rho \overline{u^{\prime} v^{\prime}}\right)}{\partial y}-\frac{\partial\left(\rho \overline{u^{\prime} w^{\prime}}\right)}{\partial z}\right] \\
& \frac{\partial(\rho V)}{\partial t}+\operatorname{div}(\rho V \mathbf{U})=-\frac{\partial P}{\partial y}+\operatorname{div}(\mu \operatorname{grad} V)+ \\
& +\left[-\frac{\partial\left(\rho \overline{u^{\prime} v^{\prime}}\right)}{\partial x}-\frac{\partial\left(\rho \overline{v^{\prime 2}}\right)}{\partial y}-\frac{\partial\left(\rho \overline{v^{\prime} w^{\prime}}\right)}{\partial z}\right] \\
& \frac{\partial(\rho W)}{\partial t}+\operatorname{div}(\rho W \mathbf{U})=-\frac{\partial P}{\partial z}+\operatorname{div}(\mu \operatorname{grad} W)+ \\
& +\left[\frac{\partial\left(\rho \overline{u^{\prime} w^{\prime}}\right)}{\partial x}-\frac{\partial\left(\rho \overline{v^{\prime} w^{\prime}}\right)}{\partial y}-\frac{\partial\left(\rho \overline{w^{\prime 2}}\right)}{\partial z}\right]
\end{aligned}
$$

$\mathrm{k}-\varepsilon$ model is one of the most popular and commonly used flow turbulence models. Two variables $(k-\varepsilon)$ require additional two transport equations, which might be written down as:

$$
\begin{gathered}
\frac{\partial(\rho k)}{\partial t}+\operatorname{div}(\rho k \mathbf{U})= \\
=\operatorname{div}\left(\frac{\mu_{t}}{\sigma_{t}} \operatorname{grad} k\right)+\mu_{t} \phi-\rho \varepsilon \\
\frac{\partial(\rho \varepsilon)}{\partial t}+\operatorname{div}(\rho \varepsilon \mathbf{U})= \\
=\operatorname{div}\left(\frac{\mu_{t}}{\sigma_{t}} \operatorname{grad} \varepsilon\right)+C_{1} \mu_{t} \frac{\varepsilon}{k} \phi-C_{2} \rho \frac{\varepsilon^{2}}{k}
\end{gathered}
$$

Variable $k$ means kinetic energy of the turbulence, while $\varepsilon$ - dissipation of that kinetic energy. The partial differential equations shown above are implemented in the calculation module of Ansys CFX programme. In order to provide a final solution to the system of equations describing turbulence flow of the fluid, it is necessary to determine boundary conditions which ensure unambiguity of the solution and determine the course of the calculation process inside the area in question.

a)

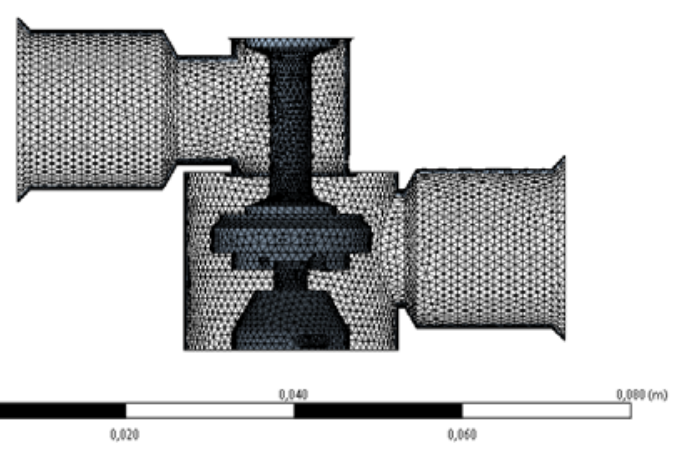

Reynolds average Average Navier-Stokes equations. 
b)

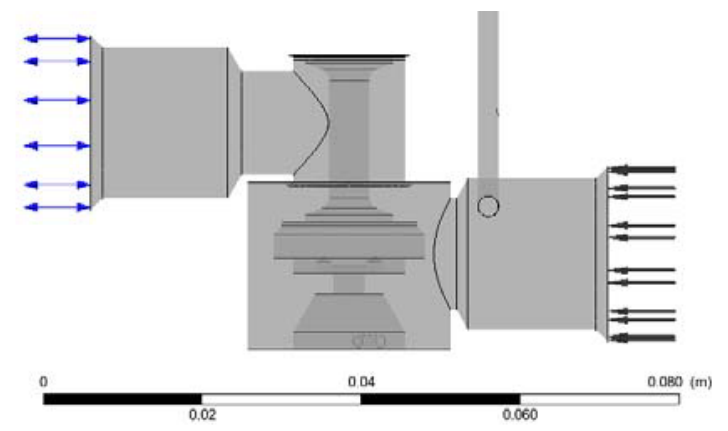

Fig. 2. a) Calculation Grid, b) Boundary Conditions.

A non-structural calculation grid with 170236 elements and 36640 nodes was used.

For further calculations, the following individual physical quantities were adopted: ambient temperature $\mathrm{T}=25{ }^{\circ} \mathrm{C}$, density $-\rho=1.185\left(\mathrm{~kg} / \mathrm{m}^{3}\right)$, reference pressure $-\mathrm{p}=101325 \mathrm{~Pa}$.

\section{Test stand}

The measuring system scheme, where a part of the elements responsible for safety was omitted, is presented below. A filter of sufficient effectiveness must be installed at the test stand. No condensate should accumulate in the connection outlets. The pipes should have a radial, smooth cross-section on the external surface. Those need to be straight and have a fixed diameter along their full length. A simplified scheme of the test stand is shown below. During measuring at the test stand, it was necessary to maintain a constant pressure at the inlet, i.e. not less than 4 bar. Subsequently, the pressure at the outlet was decreased through the throttle valve, until the mass flow rate was not increased any more. It meant that the critical flow had been achieved. At that moment, readings of the temperature and pressure at the inlet, and the flow rate and pressure at the outlet were taken.

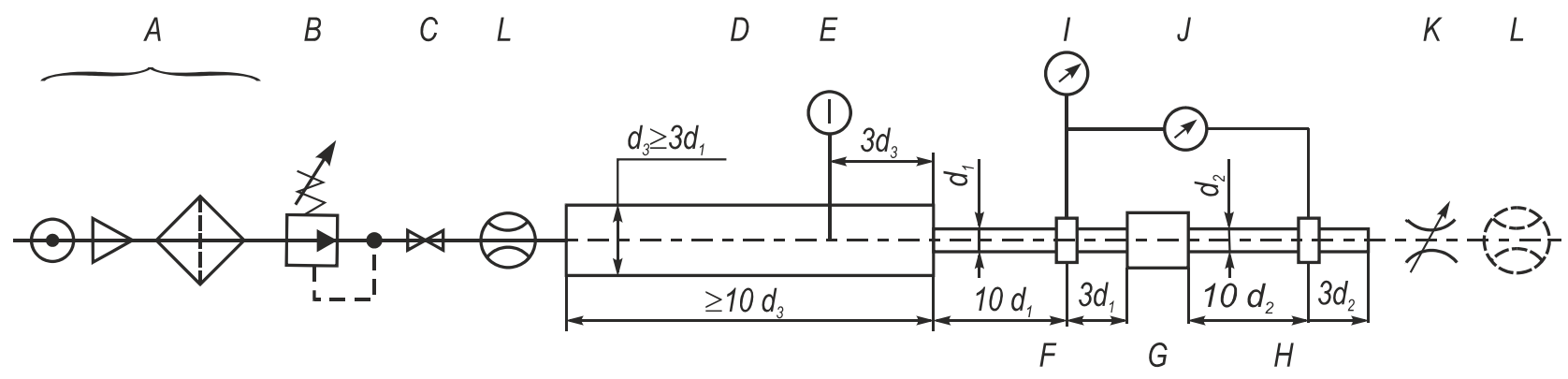

Fig. 3. Scheme of the Flow Element Measuring Test Stand.

Table. 2. Key to the test stand symbols.

\begin{tabular}{|c|c|}
\hline Symbol & Name \\
\hline A & Pressurized gas source and filter \\
\hline B & Reduction valve \\
\hline C & Shut-off valve \\
\hline D & Temperature measuring tube \\
\hline E & Temperature measuring tool \\
\hline F & Inlet Pressure measuring tube \\
\hline G & Studied element \\
\hline H & Outlet pressure measuring tube \\
\hline I & Inlet pressure measuring tool \\
\hline J & Pressure difference measuring tool \\
\hline K & Throttle Valve \\
\hline
\end{tabular}

\begin{tabular}{|l|l|}
\hline $\mathrm{L}$ & Flowmeter \\
\hline
\end{tabular}

In the next phase of the study, the throttle valve was gradually being closed in order to decrease the flow rate. The readings of all studied parameters were taken. The steps were repeated for a different flow rate. By using the reduction valve, the inlet pressure was maintained constant throughout the entire study.

\section{Comparison of the results}

This section presents a comparison of the results obtained from the numerical tests with the results achieved from the stand tests for the poppet valve.

Fig. 4 presents the characteristics obtained on the basis of the model tests and the experimental stand tests. The diagram also shows inconformity between the model test results and the experimental test results. 


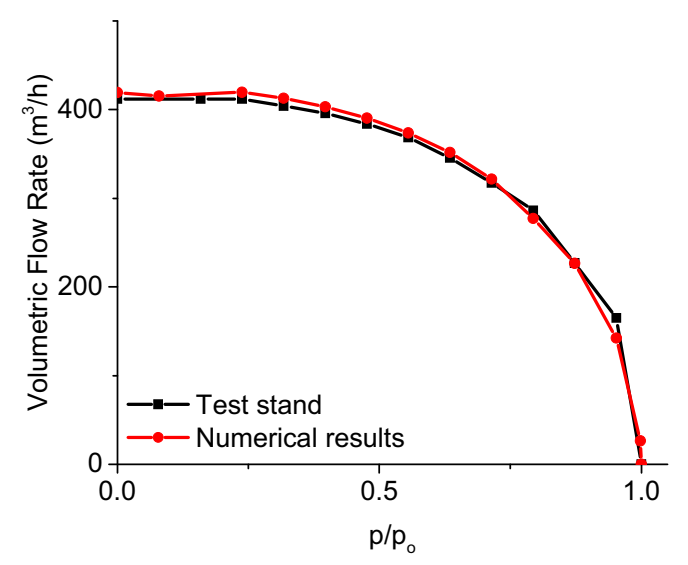

Fig. 4. Volumetric flow rate.

The differences in volumetric flow rates are small and there is a large convergence of the received results.

A relative error was calculated on the basis of the following formula:

$$
\sigma_{e r}=\frac{\left|x_{n}-x_{t s}\right|}{x_{t s}} \cdot 100 \%
$$

where:

$x_{n}$ - value from the numerical calculation,

$x_{t s}-$ value from the test stand.

and amounts to approx. $1.8 \%$.

\section{Conclusions}

The use of numerical fluid mechanics allowed to determine the pressurized air flow that goes through the valve as well as the primary flow characteristics already in the initial phase of designing the pneumatic valve. The comparison of the simulation and stand tests presented herein determined a large convergence of the results acquired. Hence, the method based on CFD might constitute an alternative to time-consuming and costly stand tests.

This research was supported in part by PLGrid Infrastructure.

\section{References}

1. J. Bochnia, Procedia Eng. 39 (0) (2012), 98-110.

2. S. Adamczak, J. Bochnia, B. Kaczmarska, Metrol. Meas. Syst. 22 (1) (2015), 127-138.

3. S. Blasiak, C. Kundera, J. Bochnia, Procedia Eng. 39 (2012), 366-378.

4. S. Blasiak, A. Pawinska, Int. J. Heat Mass Transf. 90 (2015), 710-718

5. D. Gapinski, I. Krzysztofik, (IEEE, 345 E 47TH ST, NEW YORK, NY 10017 USA, 2014).

6. D. Gapinski, I. Krzysztofik, Z. Koruba, J. Theor. Appl. Mech. 52 (3) (2014), 629-639.

7. D. Janecki, J. Zwierzchowski, L. Cedro, Bull. POLISH Acad. Sci. Sci. 63 (3) (2015), 771-779.
8. P.A. Laski, (ACAD SCI CZECH REPUBLIC, INST THERMOMECHANICS, DOLEJSKOVA 5, PRAGUE 8, 182 00, CZECH REPUBLIC, 2016).

9. E. Miko, L. Nowakowski, Procedia Eng. 39 (2012), 395404.

10. E. Miko, L. Nowakowski, Procedia Eng. 39 (2012), 405413.

11. L. Nowakowski, M. Miesikowska, M. Blasiak, (ACAD SCI CZECH REPUBLIC, INST THERMOMECHANICS, DOLEJSKOVA 5, PRAGUE 8, 182 00, CZECH REPUBLIC, 2016).

12. L. Nowakowski, E. Miko, M. Skrzyniarz, (ACAD SCI CZECH REPUBLIC, INST THERMOMECHANICS, DOLEJSKOVA 5, PRAGUE 8, 182 00, CZECH REPUBLIC, 2016).

13. L. Nowakowski, M. Wijas, (ACAD SCI CZECH REPUBLIC, INST THERMOMECHANICS, DOLEJSKOVA 5, PRAGUE 8, 182 00, CZECH REPUBLIC, 2016).

14. M. Piasecka, Int. J. Refrig. 56 (2015), 198-212.

15. M. Piasecka, Int. J. Heat Mass Transf. 81 (2015), 114-121.

16. D.S. Pietrala, (ACAD SCI CZECH REPUBLIC, INST THERMOMECHANICS, DOLEJSKOVA 5, PRAGUE 8, 182 00, CZECH REPUBLIC, 2016).

17. J.E. Takosoglu, R.F. Dindorf, P.A. Laski, Int. J. $A d v$. Manuf. Technol. 40 (3-4) (2009), 349-361.

18. J.E. Takosoglu, P.A. Laski, S. Blasiak, Proc. Inst. Mech. Eng. Part I J. Syst. Control Eng. 226 (10) (2012), 13351343.

19. J.E. Takosoglu, P.A. Laski, S. Blasiak, G. Bracha, D. Pietrala, Meas. Control. 49 (2) (2016), 62-71.

20. J. Zwierzchowski, (ACAD SCI CZECH REPUBLIC, INST THERMOMECHANICS, DOLEJSKOVA 5, PRAGUE 8, 182 00, CZECH REPUBLIC, 2016).

21. W. Inman, K. Domansky, J. Serdy, B. Owens, D. Trumper, L.G. Griffith, J. Micromechanics Microengineering. 17 (5) (2007), 891-899.

22. B. Li, L. Gao, G. Yang, Energy Convers. Manag. 67 (2013), 92-102.

23. E. Lisowski, W. Czyżycki, J. Rajda, Energy Convers. Manag. 70 (2013), 220-229.

24. M.R. Mokhtarzadeh-Dehghan, N. Ladommatos, T.J. Brennan, Appl. Math. Model. 21 (7) (1997), 437-445.

25. X. Pan, G. Wang, Z. Lu, Energy Convers. Manag. 52 (10) (2011), 3249-3256.

26. J. Qian, L. Wei, Z. Jin, J. Wang, H. Zhang, A. Lu, Energy Convers. Manag. 87 (2014), 220-226.

27. C. Srikanth, C. Bhasker, Adv. Eng. Softw. 40 (3) (2009), 193-201.

28. L. WANG, J. CUI, K. YAO, Chinese J. Chem. Eng. 16 (4) (2008), 541-546.

29. Q. Yang, Z. Zhang, M. Liu, J. Hu, Procedia Eng. 23 (2011), 543-550.

30. G.F. Bracha, (ACAD SCI CZECH REPUBLIC, INST THERMOMECHANICS, DOLEJSKOVA 5, PRAGUE 8 , 182 00, CZECH REPUBLIC, 2016).

31. M. Blasiak, (ACAD SCI CZECH REPUBLIC, INST THERMOMECHANICS, DOLEJSKOVA 5, PRAGUE 8 , 182 00, CZECH REPUBLIC, 2016).

32. P.A. Laski, J.E. Takosoglu, S. Blasiak, (ACAD SCI CZECH REPUBLIC, INST THERMOMECHANICS, DOLEJSKOVA 5, PRAGUE $8,182 \quad 00, \quad$ CZECH REPUBLIC, 2014).

33. P.A. Laski, J.E. Takosoglu, S. Blasiak, Rob. Auton. Syst. 72 (2015), 59-70.

34. S. Blasiak, J.E. Takosoglu, P.A. Laski, (ACAD SCI CZECH REPUBLIC, INST THERMOMECHANICS, DOLEJSKOVA 5, PRAGUE 8, 182 00, CZECH REPUBLIC, Svratka, CZECH REPUBLIC, 2014). 